\title{
ULTRASOUND MEASUREMENT OF FETAL KIDNEY LENGTH AS A PARAMETER FOR GESTATIONAL AGE DETERMINATION
}

\author{
By
Khaled Faraag Tawfik, Yousry Omar Salim Al-Maraghy and Wael Mohamed Hamed

Department of Obstetrics and Gynecology, Faculty of Medicine, Al-Azhar University (Assiut)

Corresponding author: Khaled Faraag Tawfik, E-mail: khaled.faraag@yahoo.com

\begin{abstract}
Background: Accuracy in estimation of gestational age (GA) has become more demanding as technology used in ultrasonography has become more advanced. Patient's expectations have also increased and they expect exact estimations to plan their pregnancies. Mean fetal kidney length (MFKL) alone or in combination with other biometric indices can be used for estimating GA more precisely.
\end{abstract}

Objective: To measure the length of fetal kidney in normal singleton pregnancies in late second and early third trimesters, its correlation with GA derived from the first day of patient known last menstrual period (LMP) and comparison with GA derived from other conventional biometric methods.

Patients and methods: This study was a prospective observational study, conducted at the department of Obstetrics \& Gynecology, Obstetrics \& Gynecology Hospital, Assiut, 500 pregnant females were enrolled in this study from March 2018 to March 2020. Those women underwent measurement of the right and left kidneys and mean was taken. Comparison between gestational ages was determined by LMP. In addition, mean fetal kidney length as well as between mean fetal kidneys length and other fetal biometric indices was done.

Results: Baseline data of enrolled women ( $\mathrm{n}=500$ ) mean age of those women was $26.31 \pm 4.87$ years. Median parity and abortion was 2 with range of both was between $0-6$ and $0-8$ times, respectively. Mean gestational age was $30.29 \pm 3.34$ weeks while mean body mass index was $19.84 \pm 1.20 \mathrm{~kg} / \mathrm{m} 2$. Average fetal kidney length was $29.88 \pm 3.33 \mathrm{~mm}$. Gestational ages based on different fetal biometric indices. Age by date had strong positive significant correlation with different fetal indices but the strongest correlation was observed with mean fetal kidney length $(r=0.96, \mathrm{P}<0.001)$. Correlation between gestational age by date and expected age by MFKL based on regression equation. That there was significant strong positive correlation between gestational age and expected age by MFKL $(r=0.97 ; \mathrm{P}<0.001)$

Conclusion: Mean fetal kidney length can be used as an accurate new parameter for estimation of gestational age in combination with BPD, HC, AC \& FL especially in late second and early third trimester (beginning from 24th week -34 th week). Using regression equation: Gestational age by date (weeks) $=1.56+0.97$ (MKL in $\mathrm{mm}$ ).

Keywords: Ultrasound measurement, Fetal kidney length, Gestational age determination.

\section{INTRODUCTION}

An accurate estimation of gestational age is fundamental to the management of all pregnancies, especially high-risk pregnancies. In some cases early, termination is necessary as soon as fetus becomes mature e.g. severe preeclampsia, eclampsia, chronic 
hypertension, chronic renal disease, severe intrauterine growth restriction (IUGR), patient with diabetes, central placenta previa, sensitized $\mathrm{Rh}$ negative mother. After 24 weeks, the symphysio-fundal height in centimeters approximates to the number of weeks up to 36 weeks of gestation. However, a number of factors influence the measurement including multiple gestation, IUGR, diabetic pregnancy, maternal size, variation in fetal lie \& engagement as well as inter \& intra observer measurement (Bardhan et al., 2016).

The development of diagnostic ultrasound has opened new possibilities for more confident assessment of dating. Gestational age (GA) can be estimated in the first trimester by ultrasonic measurement of diameter and volume of gestational sac (GS) as well as crownrump length (CRL) (Bailey et al., 2012).

Other biometric indices such as fetal biparietal diameter (BPD), femur length (FL), trans cerebellar diameter (TCD), clavicle length (CL), foot length, and head circumference (HC) are used for GA estimation during different pregnancy trimesters (Toosi and Rezaie-Delu, 2013).

Ultrasonic measurement of fetal biometry include crown- rump length (CRL), biparietal diameter (BPD) and femur length (FL) are considered to be reliable when they are performed in first $\&$ early second trimester ( $<24$ weeks) (Broere-Brown et al., 2016).

Although fetal biometry measurements indicated accurate indices for GA estimation in the early second trimester, the biological diversity of size lead to change in accuracy of these parameters as the age of fetus advanced and true dating in late second or third trimester is difficult (Lobo et al., 2011).

Fetal kidney shows variation in its width and antero-posterior dimensions, in some condition like intrauterine growth retardation. However, its length shows no significant change with any underlying medical condition (Kansaria and Parulekar, 2010). A steady growth of 1.1 $\mathrm{mm} /$ gestational week throughout the pregnancy unaffected by any underlying growth abnormalities (Ahmadi et al., 2015).

Sonographic measurements of fetal parameters are the basis for accurate determination of gestational age and detection of fetal growth abnormalities. Selection of the most useful single biometric parameter depends on the timing and purpose of measurement. It is influenced by various factors where in second and third trimester kidney length estimation was much better to depend upon as a single parameter than BPD which is much affected by engaged head and also better than abdominal circumference (AC) that is affected by IUGR. Establishing the gestational age of the fetus, especially in late trimester is a challenge to aptly treat the pregnant woman. Ultrasound parameters like BPD, $\mathrm{HC}, \mathrm{AC}$ and FL in second and third trimesters are not very reliable for dating the pregnancy. Fetal kidney length has been studied and shown to strongly correlate with the gestational age in late trimesters even in IUGR fetuses (Shivalingaiah et al., 2014).

The aim of this study was to measure the length of fetal kidney in normal singleton pregnancies in late second and early third trimesters, its correlation with 
GA derived from the first day of patient known last menstrual period (LMP) and comparison with GA derived from other conventional biometric methods.

\section{PATIENTS AND METHODS}

This study was a prospective observational study. It was conducted on 500 female patients attending the Department of Obstetrics and Gynecology, Obstetrics \& Gynecology Hospital, Asyut. All women were collected from the inpatient wards and outpatient clinics from March 2018 to March 2020.

\section{Inclusion criteria:}

Viable normal singleton pregnant women in their late $2^{\text {nd }}$ and early $3^{\text {rd }}$ trimesters (beginning from $24^{\text {th }}$ week $34^{\text {th }}$ week), who had regular menstrual cycle and were certain of their LMP, and those with first trimester obstetric dating using CRL.

\section{Exclusion criteria:}

Multiple gestations, gestational diabetes mellitus, Pre-eclampsia, uncertain of LMP, oligohydraminos, dilated renal pelvis $>4 \mathrm{~mm}$. suggested fetal chromosomal or congenital anomalies, abnormal renal morphology (nephromegaly, agenesis, hypoplasia, cyst, polycystic kidney, hydronephrosis, etc.), obscured adrenal and renal border or margin and gross maternal obesity.

\section{All patients were subjected to:}

\section{History taking:}

- Complete history taking with special emphasis on: Patient menstrual history, date of last menstrual period for confirmation of gestational age.
- Expected date of delivery was calculated according to Naegle's formula: $\mathrm{EDD}=\mathrm{LMP}+7$ days +9 months.

\section{Measurement technique:}

Ultrasound were conducted on patients met the inclusion criteria using A GE Logiq P5 ultrasound machine. All cases were scanned by routine sonographic evaluation. The average gestational age using Headlock's formula from fetal biometric indices (abdominal circumference, head Circumference, femur length and biparietal diameter) were measured and data were recorded. The renal length was measured also.

\section{Measurement of kidney length:}

A satisfactory transverse plane of fetus defined at level of the four chambers of heart, following which Moving the probe caudally in transverse section just below the level for abdominal circumference measurement, kidneys are identified. Once kidneys are located probe rotated longitudinally till full length of kidney was identified for its length calculation. The largest longitudinal image showing both superior and inferior outer poles of each kidney obtained and frozen on the monitor screen, using electronic calipers, kidney length was measured from superior outer pole to the inferior outer pole as described by (Bardhan et al., 2016).

The right and left kidneys were measured and care should be taken to exclude the adrenal glands in measurement. Comparison between gestational ages was determined by LMP, in addition mean fetal kidney length as 
well as between fetal kidneys length and other fetal biometric indices.

The study was approved by the Scientific Ethical Committee of Faculty of Medicine, Al-Azhar University. An informed written consent was taken from each participant in the study.

\section{Statistical analysis:}

Recorded data were analyzed using the statistical package for the social sciences, version 20.0 (SPSS Inc., Chicago, Illinois, USA). Quantitative data were expressed as mean \pm standard deviation (SD). Pvalue $<0.05$ was considered significant. ANOVA, correlation coefficient and regression analysis were applied.

\section{RESULTS}

Baseline data of enrolled women $(n=$ 500): Mean age of those women was $26.31 \pm 4.87$ years. Median parity and abortion was 2 with range of both was between 0-6 and 0-8 times, respectively. Mean gestational age was $30.29 \pm 3.34$ weeks while mean body mass index was $19.84 \pm 1.20 \mathrm{~kg} / \mathrm{m} 2$. Average fetal kidney length was $29.88 \pm 3.33 \mathrm{~mm}$. Gestational ages based on different fetal biometric indices (Table 1).

Table (1): Baseline data of enrolled women $(n=500)$

\begin{tabular}{|l|c|}
\hline & $\mathbf{N}=\mathbf{5 0 0}$ \\
\hline Age (years) & $26.31 \pm 4.87$ \\
\hline Parity & $2(0-6)$ \\
\hline Abortion & $2(0-8)$ \\
\hline Gestational age (weeks) & $30.29 \pm 3.34$ \\
\hline Body mass index (kg/m ${ }^{2}$ ) & $19.84 \pm 1.20$ \\
\hline Gestational age based one fetal biometric indices: & \\
Biparietal diameter & $29.98 \pm 3.39$ \\
Head circumference & $30.73 \pm 3.46$ \\
Femur length & $30.52 \pm 3.43$ \\
Abdominal circumference & $29.58 \pm 3.25$ \\
\hline Mean Fetal kidney length & $29.88 \pm 3.33$ \\
\hline
\end{tabular}

Data were expressed as mean (SD), median (range), frequency (percentage)

It was noticed that gestational age by date had strong positive significant correlation with different fetal indices but the strongest correlation was observed with mean fetal kidney length $(\mathrm{r}=0.96, \mathrm{P}<$ 0.001) (Table 2).

Table (2): Correlation between gestational age and different fetal biometric indices.

\begin{tabular}{|c|c|c|}
\hline Getal indices & $\mathrm{r}$ & $\mathrm{P}$ \\
\hline Biparietal diameter & 0.94 & $<0.001$ \\
\hline Head circumference & 0.92 & $<0.001$ \\
\hline Femur length & 0.94 & $<0.001$ \\
\hline Abdominal circumference & 0.89 & $<0.001$ \\
\hline Mean Fetal kidney length & 0.96 & $<0.001$ \\
\hline
\end{tabular}

$\mathrm{P}$ indicates significance of correlation; $\mathrm{r}$ is the correlation efficient. 
- Gestational age by date based on biparietal diameter $($ BPD $)=2.41+0.93$ (BPD). The analysis of variance (ANOVA) showed significant relation between gestational age by date and BPD where BPD could explain as much as $89 \%$ of variation in the gestational age $(\mathrm{R} 2=$ $0.89, \mathrm{DF}=1, \mathrm{P}<0.001)$.

- $\quad$ Gestational age by date based on head circumference $(\mathbf{H C})=2.98+0.89$ (HC). The analysis of variance (ANOVA) showed significant relation between gestational age by date and $\mathrm{HC}$ where it could explain as much as $84 \%$ of variation in the gestational age $(\mathrm{R} 2=0.84, \mathrm{DF}=1$, $\mathrm{P}<0.001)$.

- $\quad$ Gestational age by date based on femur length $(\mathbf{F L})=2.18+0.92(\mathrm{FL})$. The analysis of variance (ANOVA) showed significant relation between gestational age by date and FL where it could explain as much as $89 \%$ of variation in the gestational age $(\mathrm{R} 2=0.89, \mathrm{DF}=1$, $\mathrm{P}<0.001$ ).

\section{- $\quad$ Gestational age by date based on} abdominal circumference $(\mathrm{AC})=3.04+$ 0.92 (AC). The analysis of variance (ANOVA) showed significant relation between gestational age by date and $\mathrm{AC}$ where it could explain as much as $80 \%$ of variation in the gestational age $(\mathrm{R} 2=0.80$, $\mathrm{DF}=1, \mathrm{P}<0.001)$.

- $\quad$ Gestational age by date based on mean fetal kidney length $($ MFKL) = $1.56+0.97$ (FKL). The analysis of variance (ANOVA) showed significant relation between gestational age by date and FKL where it could explain as much as $93 \%$ of variation in the gestational age $(\mathrm{R} 2=0.93, \mathrm{DF}=1, \mathrm{P}<0.001)$.

- $\quad$ Based on the current result, MFKL had the best fit line and regression equation where it had the highest slope (0.97), least intercept (1.56) and highest adjusted R2 (0.93) (Tables 3 \& 4).

Table (3): Regression analysis for gestational age by date with other fetal indices

\begin{tabular}{|c|c|c|c|c|}
\hline & Intercept & Slope & $\mathbf{R}^{\mathbf{2}}$ & Regression equation \\
\hline BPD & 2.41 & 0.93 & 0.89 & $2.41+0.93(\mathrm{BPD})$ \\
\hline HC & 2.98 & 0.89 & 0.84 & $2.98+0.89(\mathrm{HC})$ \\
\hline FL & 2.18 & 0.92 & 0.89 & $2.18+0.92(\mathrm{FL})$ \\
\hline AC & 3.04 & 0.92 & 0.80 & $3.04+0.92(\mathrm{AC})$ \\
\hline MFKL & 1.56 & 0.97 & 0.93 & $1.56+0.97(\mathrm{FKL})$ \\
\hline
\end{tabular}

BPD: biparietal diameter; HC: head circumference; FL: femur length; AC: abdominal circumference; MFKL: Mean fetal kidney length

Table (4): ANOVA for relation between gestational age by date and different indices

\begin{tabular}{|c|c|c|c|c|}
\hline & DF & F ratio & $\mathbf{R}^{\mathbf{2}}$ & P value \\
\hline BPD & 1 & 39.85 & 0.89 & $<0.001$ \\
\hline HC & 1 & 22.42 & 0.84 & $<0.001$ \\
\hline FL & 1 & 34.96 & 0.89 & $<0.001$ \\
\hline AC & 1 & 35.81 & 0.80 & $<0.001$ \\
\hline MFKL & 1 & 41.07 & 0.93 & $<0.001$ \\
\hline
\end{tabular}

BPD: biparietal diameter; HC: head circumference; FL: femur length; AC: abdominal circumference; MFKL: mean fetal kidney length; ANOVA: analysis of variance

Frequency distribution of fetal kidney length:
Plotting the observed versus expected Z-scores (Q-Q plot) and observed values and expected z-score (normal plot) of the 
mean fetal kidney length showed an approximately linear relation between the two parameters denoting normality also displayed in the histogram that shows mild right and left skewness of the frequency distribution of mean fetal

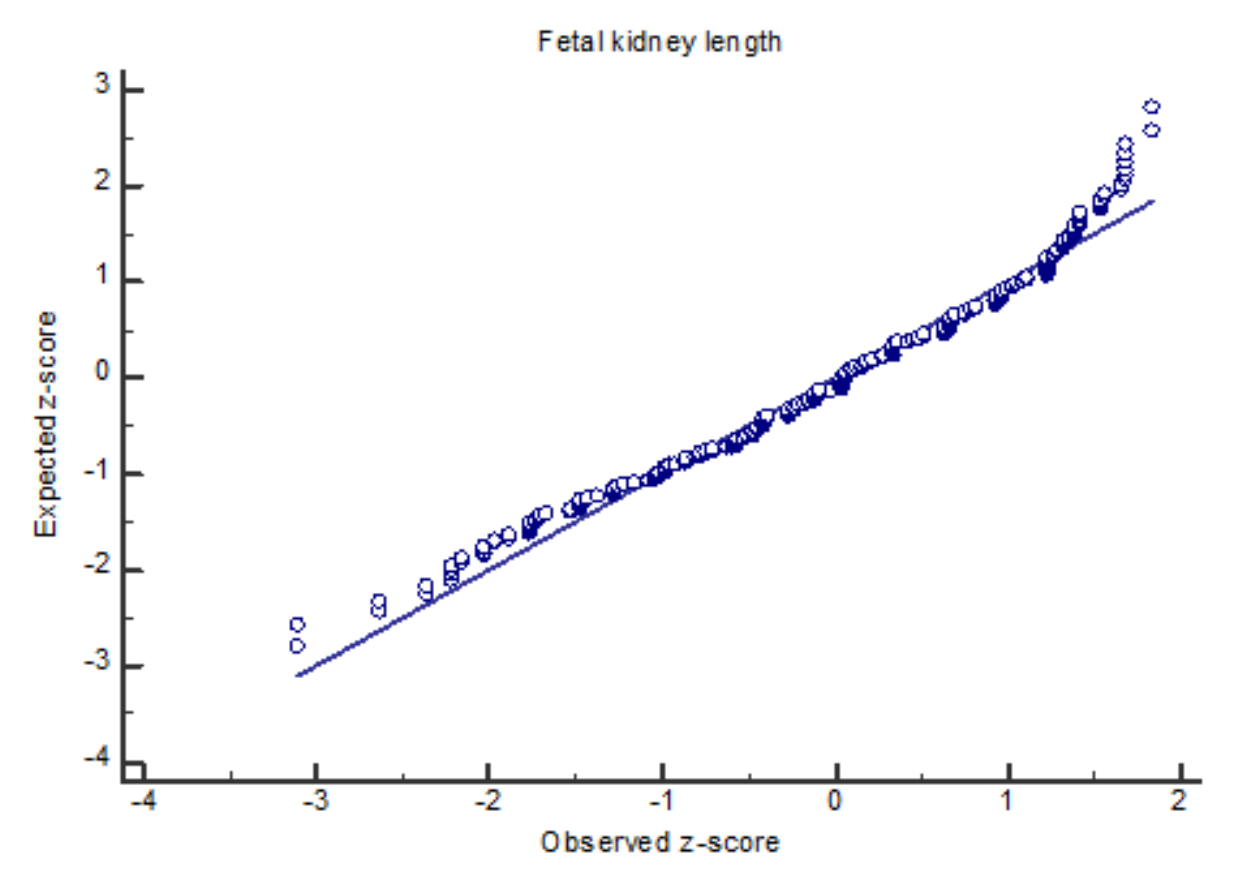

distribution of fetal kidney length. This is kidney length.

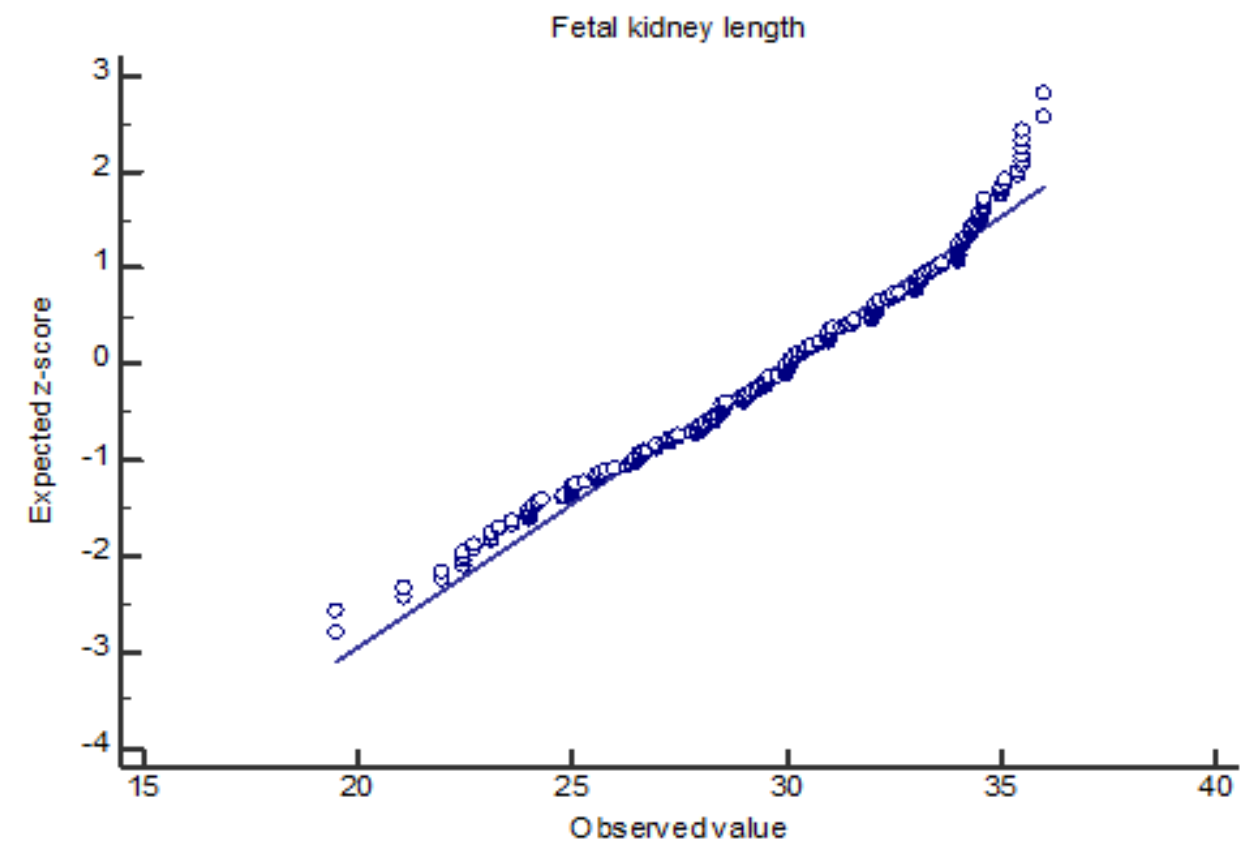

Figure (2): Frequency distribution of mean fetal kidney length by Q-Q plot Figure (3): Frequency distribution of mean fetal kidney length by normal plot 


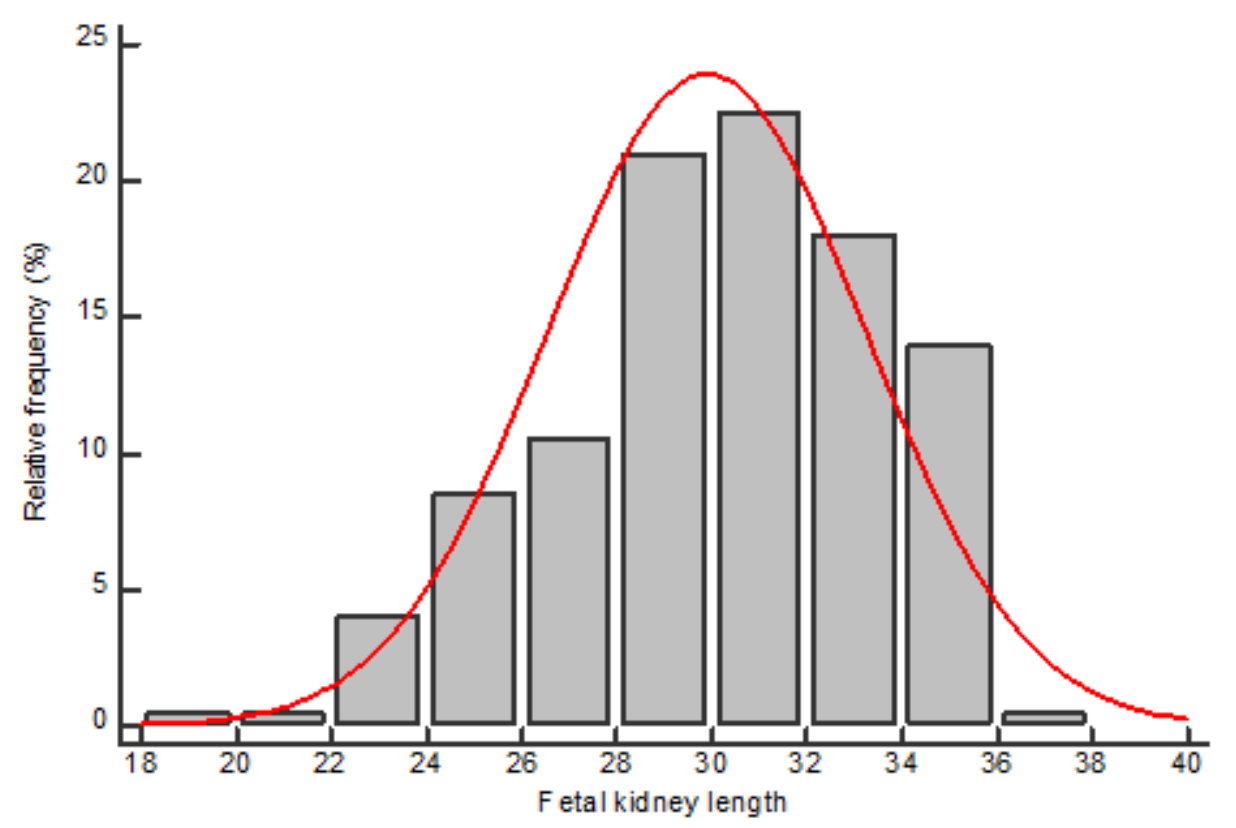

Figure (4): Frequency distribution of mean fetal kidney length by histogram

Correlation between gestational age by date and expected age by MFKL based on regression equation: As previously mentioned that gestational age by date based on mean fetal kidney length equation as following; $1.56+0.97$ (MFKL). It was noted that there was significant strong positive correlation between gestational age and expected age by MFKL ( $\mathrm{r}=0.97 ; \mathrm{P}<0.001)$.

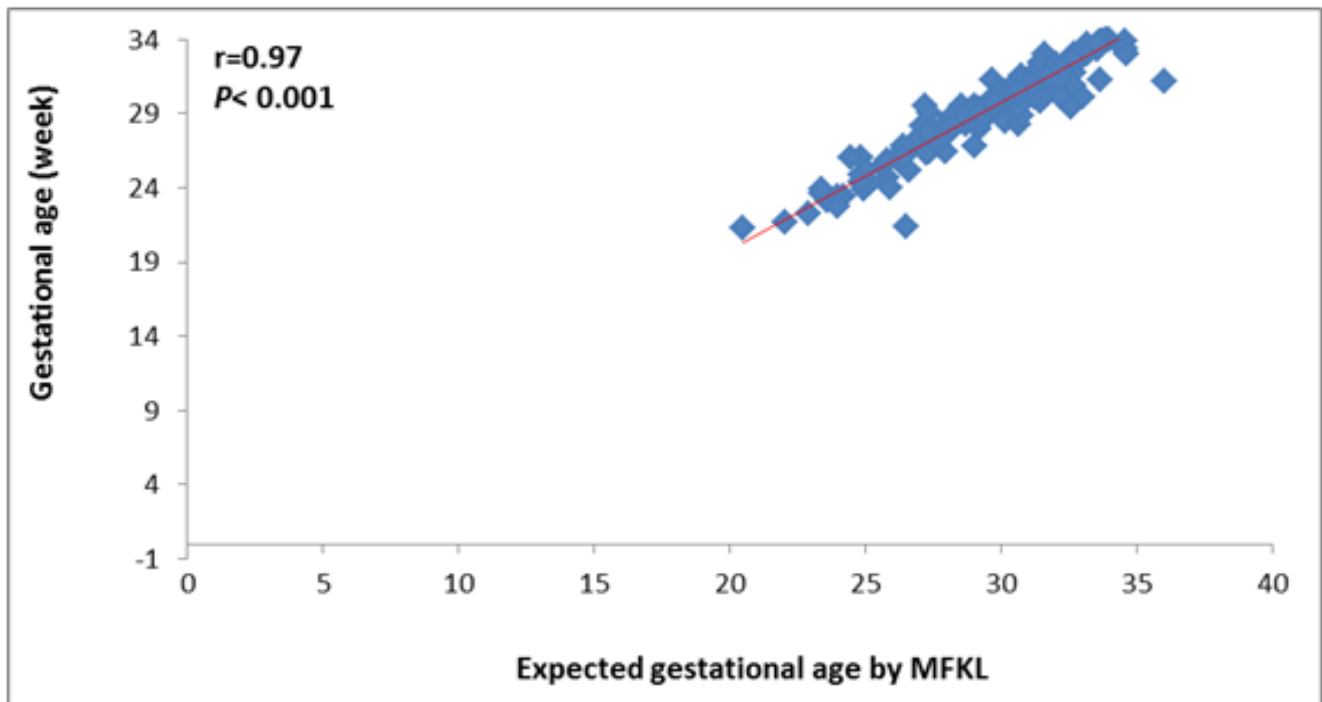

(MFKL) could be calculated by regression

Figure (5): Correlation between gestational age by date and expected age by MFKL

Assessment the overall accuracy of regression equation for FKL: To assess overall accuracy of regression equation of
MFKL for prediction the gestational age, standard error of the estimate (SEest, oest) 
should be calculated. It could be calculated from the following equation;

SEest $=\sqrt{\frac{\Sigma\left(\mathbf{Y}-\mathbf{Y}^{\prime}\right)^{2}}{\mathbf{N}}}= \pm 6.88$ days

Where; SEest: standard error of the estimate; Y: actual gestational age; Y':

\section{DISCUSSION}

An accurate estimation of gestational age is fundamental to the management of all pregnancies, especially high-risk pregnancies. Previous studies concluded that fetal kidney Length can be used to accurately date the pregnancy even in difficult situations (engaged head, fetal IUGR, macrosomia, malformation etc.) (Galal et al., 2012).

Galal et al. (2012) stated that strong correlation exists between renal length and gestational age. It is determined by biparietal diameter, femoral length, and abdominal circumference, and an average of the three. No significant difference was found between right and left renal lengths in fetuses in which both kidneys were imaged.

Toosi and Rezaie-Delu (2013) aimed to evaluate the normal fetal kidney length (KL) and its correlation with GA. A crosssectional study on 92 pregnant women with normal singleton pregnancy underwent standard ultrasound fetal biometry and kidney length measurement. Univariate and multivariate linear regression analysis was used to create a predictive equation to estimate GA on the KL and fetobiometry parameters. A significant correlation was found between GA and KL. The best GA predictor was obtained by combining head circumference, fetal biparietal diameter, femur length and KL. The findings expected gestational age by MFKL; N: total sample size

This indicated that SEest of regression equation of MFKL for prediction the gestational age was \pm 6.88 days. This may be accepted for the clinical practice.

showed that KL measurements combination with other fetal biometric parameters could predict age of pregnancy with a better precision.

Shivalingaiah et al. (2014) stated that fetal kidney length is strongly correlated with the gestational age in late trimesters even in IUGR fetuses $(r=0.85)$. The study evaluated the role of kidney length in determining the gestation age of 60 pregnant women between 24 - 36 weeks of gestation whose pregnancies were dated accurately by early dating scan. Length of the nearer kidney was measured in centimeters, 4 weekly in the longitudinal axis along with other biometric indices. According to the observations, the mean deviation from the gestational age at all the weeks is least for KL. The result indicates that the kidney length in the present study correlated well with the assigned gestational age and found almost same as all the ultrasound biometric parameters put together.

In our study, the mean kidney length correlated well with the assigned gestational age. A strong Pearson's correlation between the mean fetal kidney length and gestational age was obtained similar to the previously reported results of Kaul et al. (2011), Toosi and RezaieDelu (2013), Shivalingaiah et al. (2014) and Ugur et al. (2016). Standard error of the estimate in our study, varied with Toosi and Rezaie-Delu (2013) and Peter 
et al. (2017). This might be contributed to difference in ultrasound machines used or may be due to difference in operator efficiency. The present study derived an equation for estimation of the gestational age from the mean fetal kidney length.

\section{CONCLUSION}

Mean fetal kidney length can be used as an accurate new parameter for estimation of gestational age in combination with BPD, HC, AC and FL. Especially in late second and early third trimester (beginning from 24th week 34 th weeks). Using regression equation

Regression Equation: Gestational age by date $($ weeks $)=1.56+0.97(\mathrm{MKL}$ in $\mathrm{mm})$.

\section{RECOMMENDATIONS}

Fetal kidney length could be used as an accurate new parameter for estimation of gestational age in combination with BPD, $\mathrm{HC}, \mathrm{AC}$ and FL. Other prospective randomized, controlled trials are necessary to determine the significance of fetal kidney length in late third trimester and in IUGR fetuses.

\section{REFERENCES}

1. Ahmadi F, Taqi Dizaj AV, Akhbari F, Hohreh IS and Holamreza KG (2015): Fetal kidney measurement in 26-39 weeks gestation in normal fetuses of Iranian pregnant women. J Preg Child Health, 2: 139-142.

2. Bailey C, Carnell J, Vahidnia F, Shah S, Stone M, Adams M and Nagdev A (2012): Accuracy of emergency physicians using ultrasound measurement of crown-rump length to estimate gestational age in pregnant females. Am J Emerge Med., 30(8):1627-1629.

3. Bardhan J, Ghosh SK, SarKar KN and Sar Kar M. (2016): Fetal kidney length as a parameter for gestational age determination and its comparative evaluation with other fetal biometric indices. IAIM, 3(8): 36-44.

4. Broere-Brown ZA, Baan E, SchalekampTimmermans S, Verburg BO, Jaddoe WV and Steegers AE (2016): Sex-specific differences in fetal and infant growth patterns: a prospective population-based cohort study. Biol Sex Differ., 7: 65-69.

5. Galal M, Symonds I, Murray H, Petraglia F and Smith $R$ (2012): Postterm pregnancy. Facts Views Vis Obgyn., 4(3): 175-187.

6. Kansaria $J$ and Parulekar S (2010): Nomogram for Foetal Kidney Length. Bombay Hospital Journal, 51(2): 155-162.

7. Kaul I, Menia V, Anand AK and Gupta $R$ (2011): Role of fetal kidney length in estimation of gestational age. JK Science, 14(2):65-69.

8. Lobo ML, Favorito LA, Abidu-Figueiredo $M$ and Sampaio FJ (2011): Renal pelvic diameters in human fetuses: anatomical reference for diagnosis of fetal hydronephrosis. Urology, 77(2):452-457.

9. Peter M, Nayak AK, Giri PP and Jain MK (2017): Fetal kidney length as a parameter for determination of gestational age from 20th week to term in healthy women with uncomplicated pregnancy. IJRMS, 7:5-9.

10. Shivalingaiah N, Sowmya K, Kanmani TR and Marimuthu P (2014): Fetal kidney length as a parameter for determination of gestational age in pregnancy. IN J Report Contraception Obstetric Gynecologic, 3:424-427.

11. Toosi FS and Rezaie-Delu H (2013): Evaluation of the Normal Fetal Kidney Length and Its Correlation with Gestational Age. Acta Medica Iranica, 51(5): 303-306.

12. Ugur MG, Mustafa A, Ozcan HC, Tepe NB, Kurt H, Akcil E and Gunduz R (2016): Fetal kidney length as a useful adjunct parameter for better determination of gestational age. Saudi Med J., 37(5): 533-537. 


\section{قياس طول الكُلى للجنين باستخدام الموجات فوق الصوتية كمعيار لتحديد العمر الرحمي بامي لخدي}

خالد فراج توفيق, يسرى عمر سليم المراغى, وائل محمد حامد

قسم التوليد وأمر اض النساء، كلية الطب، جامعة الأزهر (أسيوط)

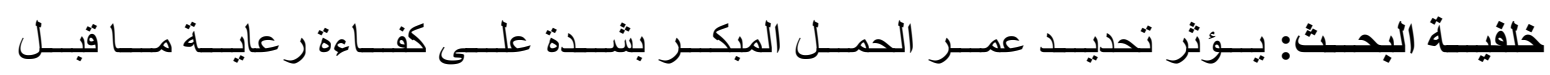

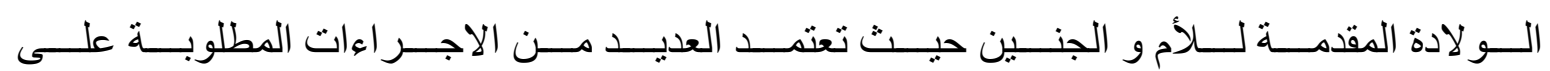

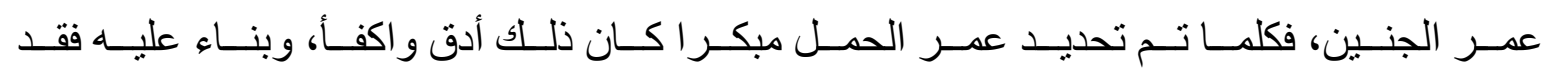
قامت العديد من الأبحاث بالتطرق لأفضل الطرق لتحديد عمر الحمل.

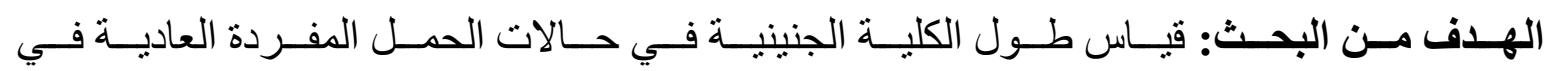

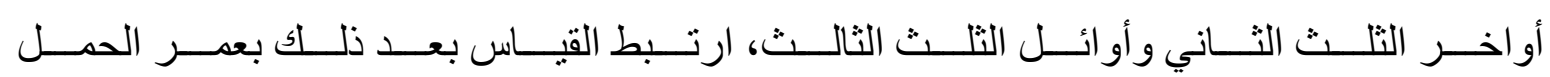

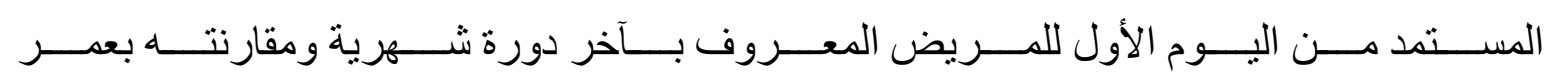

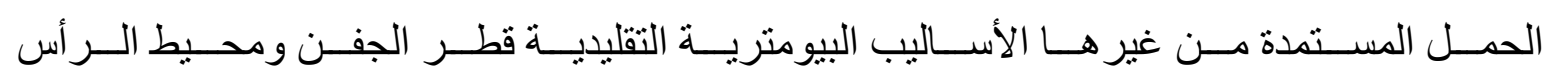
ومحيط البطن وطول عظم الفخذ.

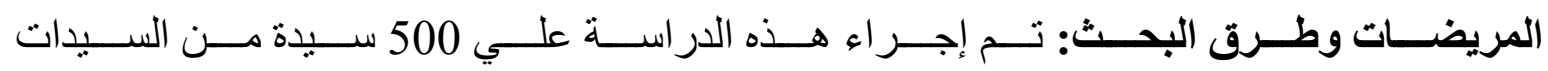

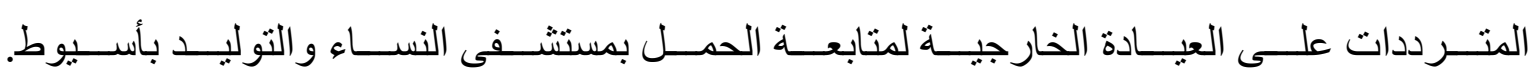

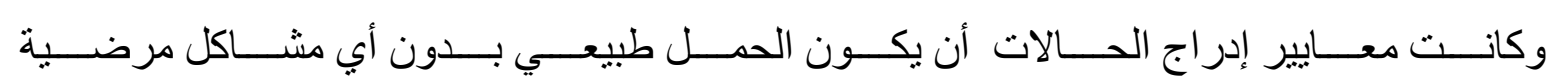

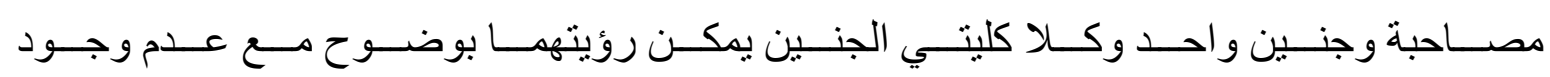

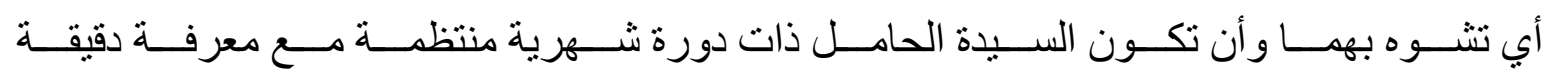

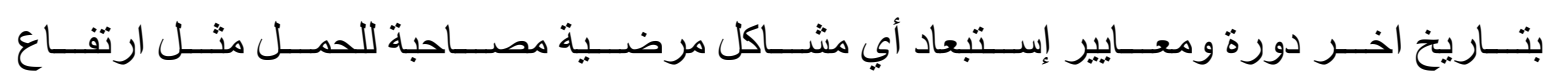

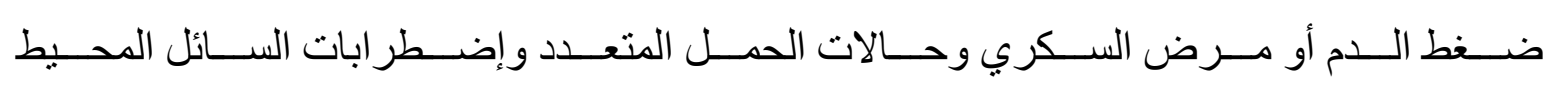
بالجنين.

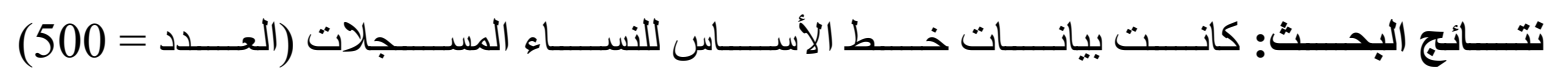

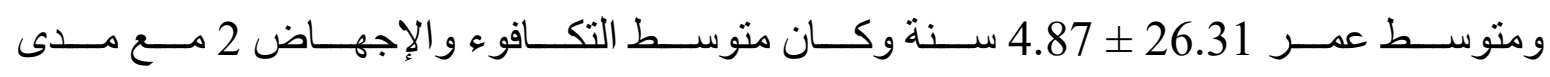

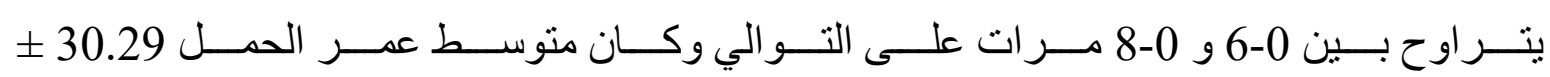

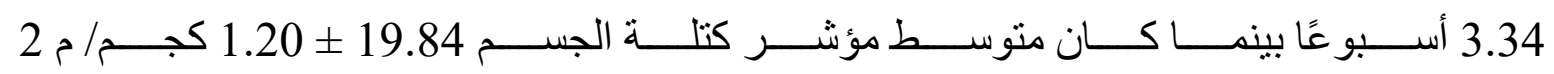

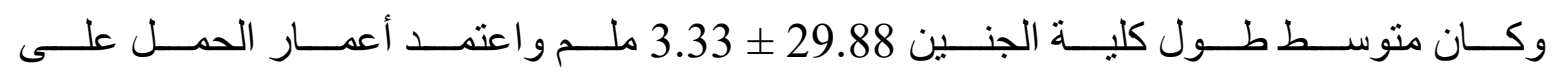




\section{ULTRASOUND MEASUREMENT OF FETAL KIDNEY LENGTH...}

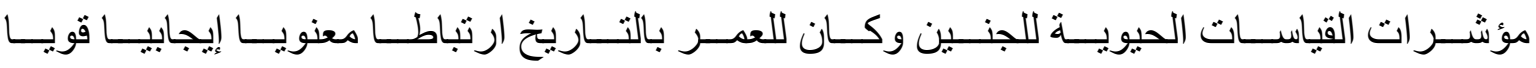

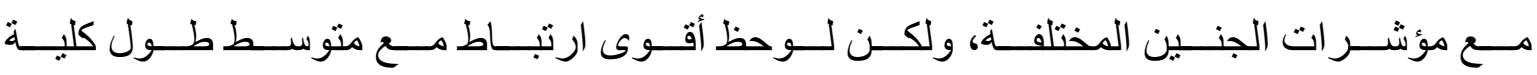

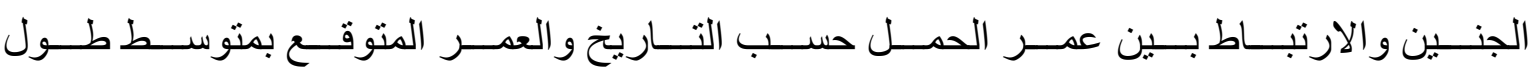

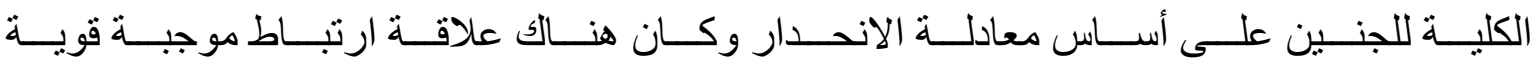
بين عمر الحمل والعمر المتوقع بمتوسط طول كلية الجنين.

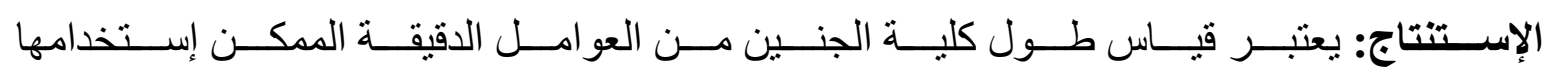
لقياس عمر الحمل. 